ensaio

$\operatorname{vol} 8 \cdot \mathrm{n}^{\circ} 2 \cdot \operatorname{dez} .2006$

\title{
MODELOS E MODELIZAÇÕES NO ENSINO: UM ESTUDO DA CADEIA ALIMENTAR
}

\section{Models and modelizations in education: a study of the alimentary chain}

\author{
Alfredo Müllen da Paz ${ }^{1}$ \\ Ilse Abegg ${ }^{2}$ \\ José de Pinho Alves Filho ${ }^{3}$ \\ Vera Lúcia Bahl de Oliveira ${ }^{4}$
}

RESUMO:

Este trabalho aborda o processo de modelização no Ensino de Ciências Naturais, mais especificamente no ensino de Biologia. Primeiramente, abordam-se conceitualmente modelos e modelizações no ensino de ciências. Após esse procedimento é apresentado o exemplo de modelização da cadeia alimentar e, por fim, descreve-se uma situação transcorrida em sala de aula na qual é analisado o processo de ensino aprendizagem, mediado pelos modelos. Para tanto, utilizou-se uma situação didática desenvolvida na 4⿳亠丷厂 série do ensino fundamental sobre o tema "cadeia alimentar". Foram utilizados nesse processo de ensino, os modelos e representações apresentadas em livros didáticos de diferentes séries, inclusive dos níveis médio e superior. Como conclusões, apontamos que os modelos devem ser utilizados como recursos aproximativos e não como realidades; como instrumentos de explicação e previsão produzidos com a intenção de uma melhor compreensão dos problemas educativos enfrentados. Nesse processo, é fundamental o papel do professor na implementação das situações de interação e aprendizagem necessárias. Palavras-chave: Modelos e modelizações, ensino de ciências, Cadeia Alimentar.

\section{ABSTRACT:}

This work approaches the process of modelization in the Natural Science Teaching, more specifically in the teaching of Biology. First, models and modelizations in the teaching of sciences are approached conceptually. After, the example of modelization of the alimentary chain is presented and finally, describes a situation occured in classroom in which the process of teaching learning, mediated for the models is analyzed. For in such a way, a didactic situation developed in $4^{\mathrm{a}}$ was used series of basic education on the subject "alimentary chain". They had been used in this process of teaching, the models and representations presented in didactic books of different series, also of the average and superior level. As conclusions we point that the models must be used as aproximativos resources and not as realities. As instruments of explanation and forecast produced with the intention of one better understanding of the faced educative problems. In this process, the paper of the professor is basic, in the implementation of the situations of necessary interaction and learning.

Keywords: Models and modelization; teaching of sciences; Alimentary Chain

\footnotetext{
1Professor do Colégio de Aplicação da Universidade Federal de Santa Catarina (CA/UFSC) e doutorando do Programa de Pós-Graduação em Educação Científica e Tecnológica, UFSC, Santa Catarina, Brasil (e-mail: apaz@ca.ufsc.br).

${ }^{2}$ Mestre em Educação Científica e Tecnológica pela Universidade Federal de Santa Catarina, Brasil (e-mail: iabegg@mail.ufsm.br).

${ }^{3}$ Professor adjunto do Departamento de Física da Universidade Federal de Santa Catarina e do Programa de Pós-Graduação em Educação Científica e Tecnológica, UFSC, Santa Catarina, Brasil (e-mail: jopinho@fsc.ufsc.br).

${ }^{4}$ Professora assistente do Departamento de Biologia Geral da Universidade Estadual de Londrina, Paraná, e doutoranda do Programa de PósGraduação em Educação Científica e Tecnológica, UFSC, Santa Catarina, Brasil (e-mail: oliveir@sercomtel.com.br).
} 


\section{INTRODUÇÃO}

Os estudos de modelos e modelizações ${ }^{5}$ de diversos autores, Bunge (1974), Astolfi (2001), Bassanesi (1994), Martinand (1986), Pietrocola (1999), Pinheiro (1996, 2001), mostrou-nos a aplicabilidade dessas teorias na área das ciências exatas, e mais especificamente na matemática. Enveredar por um estudo, envolvendo modelos e modelização de um conteúdo das ciências biológicas, mostrou-se uma tarefa extremamente ousada. Primeiramente, porque são poucas as publicações que discutem essa relação e ainda, porque os autores são de formação diversificada (dois ligados ao ensino de física, um ligado ao ensino de biologia e o quarto ligado ao ensino de ciências nas séries iniciais), configurando-se assim, um estudo multidisciplinar.

Utilizando-se das conceituações teóricas de modelos, enfrentamos o desafio de estudar uma seqüência programática envolvendo a modelização de uma cadeia alimentar, implementada em uma $4^{a}$ série do ensino fundamental de uma escola pública. A primeira constatação é que uma seqüência, como por exemplo: capim ? caramujo ? passarinho ? gato (cadeia alimentar) é um modelo. Assumindo essa premissa, cadeia alimentar é uma representação conceitual esquemática de uma situação real, na qual há uma seqüência de seres vivos relacionados unidirecionalmente pelo fluxo de energia. Assim sendo, abordamos teoricamente modelos e modelizações no Ensino de Ciências Naturais e suas Tecnologias - CN\&T, descrevemos uma situação transcorrida em sala de aula e analisamos o processo de ensino aprendizagem, mediados pelos modelos.

\section{MODELOS E MODELIZAÇÃO NO ENSINO DE CIÊNCIAS NATURAIS E SUAS TECNOLOGIAS}

Em nossa discussão, iremos nos referenciar basicamente nas idéias de Mario Bunge (1974), em particular sobre a sua maneira de conceber as relações entre as teorias e a realidade, ou seja, como os modelos podem oferecer uma forma de conceber o realismo científico sem no entanto identificá-lo com as formas mais ingênuas que acabam por propor as teorias científicas como imagens refletidas da realidade.

As discussões do trabalho de Bunge (1974) sobre modelos e modelização iniciamse pela análise da função dos modelos na constituição do conhecimento teórico das ciências. Segundo o autor, a Ciência desenvolvida pelas sociedades modernas tem a capacidade de produzir conhecimento teórico diferente das sociedades pré-industriais, onde a crença, opinião e conhecimento pré-teórico eram suficientes. A ciência contemporânea não é somente experiência, é sim, teoria mais experiência planificada, executada e entendida à luz de teorias.

No campo educacional, a utilização de modelos mais simples é aceitável na medida que seus objetivos sejam facilitar a compreensão, ou seja, que esses não se tornem modelos em que se sujeitem à fundamentação teórica não relevante. Para Fourez (1997), a simplificação do modelo não é considerada como um inconveniente, mas uma necessidade. Deter-se na complexidade dos modelos é essencial para a gestão científica.

Para Bunge, segundo Pietrocola (1999), "os modelos são abordados na medida em que se procura relações entre as teorias e os dados empíricos. Estes são os intermediários entre duas instâncias limítrofes do fazer científico: conceito e medidas."

${ }^{5}$ O termo "Modelização" advém da escola francesa, "modélisation", no livro de Astolfi (2001), remete a Bernard Walliser, Systèmes et modeles, Seuil, 1977 e também a Jean-louis Lê Moigne, La Théorie du système general. Théorie de la modélisation, Paris, PUF, $2^{\mathrm{a}}$ ed, 1984.

Para os autores "Modelagem" é o termo usado na pesquisa matemática, já "Modelização", que advem da escola francesa é usada na pesquisa de ensino de física, generalizando para o ensino de Ciências Naturais. 
Ainda, este autor ressalta que "os dados empíricos apesar de bem próximos da realidade, não podem ser inseridos em sistemas lógicos e gerar conhecimento. Desta aparente dicotomia entre teórico e empírico, a modelização pode se constituir em uma instância mediadora" (In.: Pietrocola, 1999:10).

Para chegar ao conceito da realidade, segundo Bunge (1974), parte-se das idealizações, na forma da identificação das suas características gerais. Assim, para o autor, instala-se um objeto-modelo ou modelo conceitual de uma coisa ou de um fato e se designa ao mesmo, propriedades possíveis de serem sustentadas por teorias. Os objetos modelos, "apesar do alto grau de realidade, não permitem nenhuma operacionalização que vá além do estabelecimento de semelhanças." (Pietrocola, 1999:10).

Já a construção de uma teoria do objeto-modelo requer um modelo teórico. Ressalta-se que todo modelo teórico "é parcial e aproximativo" (Bunge, 1974:30), pois somente os elementos do trabalho científico, como a observação, a intuição e a razão não permitem o conhecimento do real, mas o processo de modelização e sua comprovação apresenta um bom resultado no conhecimento da realidade. "De maneira geral, podemos dizer que um modelo é resultado de uma reflexão sobre uma parte da realidade e da tentativa de entender e ou agir sobre ela" (Bassanezi, In.: Pinheiro, 1996:75).

Os modelos e a modelização vem sendo estudados nos últimos anos no escopo da Didática das Ciências. Algumas considerações são levantadas por Astolfi (2001), que afirma que a presença da modelização em sala de aula advém "da necessidade de explicação que não satisfaz o simples estabelecimento de uma relação casual" (Astolfi, 2001:104) e os modelos científicos são apresentados para os alunos "como a realidade diretamente interpretada muito mais do que representações construtivas, conscientemente reduzidas e calculáveis" (Astolfi, 2001: 105, grifos nossos).

Para Martinand em Astolfi (2001), os modelos permitem a apreensão da realidade em virtude de dois motivos:

$\left.1^{\circ}\right)$ facilitar a representação do "escondido", pois "substituindo as primeiras representações por variáveis, parâmetros e relações entre variáveis, fazem com que se passe a representações mais relacionais e hipotéticas". (Martinand, In.: Astolfi, 2001:103).

$\left.2^{\circ}\right)$ auxiliar a pensar o "complexo", porque "identificando e manipulando bons sistemas, permitem descrever as variáveis de estado e de interação, as relações internas entre essas variáveis, os valores de imposições exteriores". (Martinand, In.: Astolfi, 2001:103).

A modelização na Didática das Ciências, para Astolfi (2001), possibilita que o aluno perceba e conceba o caráter arbitrário do modelo. $\mathrm{O}$ aluno como modelizador pode distinguir dois aspectos complementares do modelo que, necessariamente, se encontram presentes no processo de modelização: o modelo teórico e o modelo empírico. O modelo teórico está relacionado ao caráter hipotético. O modelo empírico é resultado de um tratamento de dados, tendo por base o modelo teórico.

Construir atividades de modelização, estruturando propriedades no modelo e comparando as atividades experimentais, pode facilitar aos alunos, reconhecer a diferença entre a referência empírica e os modelos, pois, "o trabalho didático sobre a modelização não se opõe ao trabalho experimental, mas sim o complementa." (Astolfi, 2001:107). O autor, deixa claro que nem todos os modelos científicos se equivalem, e cada um deles faz com que atuem especificamente três elementos que interagem entre si:

a) Uma representação com elementos visuais, como maquetes, modelos de estrutura, etc.; 


\section{ensaio}

vol $8 \cdot \mathrm{n}^{\circ} 2 \cdot \operatorname{dez} .2006$

b) Uma construção teórica que possa substituir a relação dos dados empíricos e

c) O estabelecimento de símbolos sujeitos a regras operatórias bem definidas que possam substituir os conceitos e as relações dos sistemas. Em razão do estabelecimento desses elementos, podemos afirmar que os modelos estão atrelados a natureza das disciplinas, pois "um modelo em biologia nunca atingirá a formalização de um modelo em física" (Bunge, In.: Astolfi, 2001:107).

Devemos destacar a distância entre os modelos reduzidos, construídos para descrever uma função ou organização biológica, e os modelos formalizados em forma de equações, conforme destaca Canguilhem (In.:Astolfi, 2001:107): "distância que separa a analogia do homotético e da homologia".

Visualizando dessa forma, a natureza dos modelos é que indica o estado de avanço de uma ciência ou de uma teoria: vem um momento, como diz Bunge (In.: Astolfi, 2001:107), "em que não se recorre mais aos "como se", mas em que se produzem apenas explicações literais". Entretanto, "ela está igualmente ligada à natureza das disciplinas, e um modelo em biologia nunca atingirá a formalização de um modelo em física". Bunge ressalta ainda, que se deve estar constantemente atento quanto as tentativas reducionistas do tipo físico-química, pois as mesmas podem levar a um quadro mecanicista das propriedades específicas do ser vivo.

Os modelos são a essência das teorias e podemos classificá-los em três categorias: modelo representacional, conhecido como maquete, sendo que é uma representação física tridimensional (ex. terrário, aquário, estufa, etc.); modelo imaginário, é um conjunto de pressupostos apresentados para descrever como um objeto ou sistema seria (ex. DNA, ligações químicas, etc.) e o modelo teórico, que é um conjunto de pressupostos explicitados de um objeto ou sistema (ex. sistema solar, ciclo da chuva, ciclo do carbono, etc.). Alguns modelos teóricos são expressos matematicamente.

Observadas essas condições, podemos dizer que cada vez mais se faz necessário o uso de modelos no ensino de CN\&T, seja na área de ensino de Física como na Química e Biologia, para não falar na Matemática. Para Martinand (1986), o uso de modelos possibilita ao aluno uma apreensão dos aspectos maiores da realidade seja ela natural, técnica, econômica ou social. Ainda, diz que há um duplo caráter, hipotético e sistemático que é constitutivo dos modelos que constroem as ciências e que os alunos devem, pois se apropriar.

A modelização no ensino de ciências naturais surge da necessidade de explicação que não satisfaz o simples estabelecimento de uma relação causal. Dessa forma, o professor passa a fazer uso de maquetes, esquemas, gráficos, para fortalecer suas explicações de um determinado conceito, proporcionando assim uma maior compreensão da realidade por parte dos alunos. Portanto, se para Bunge (1974) os modelos são a essência do próprio trabalho científico:

Da mesma forma acreditamos que eles devam também o ser para o ensino de ciências, pois ao construirmos modelos exercita-se a capacidade criativa com objetivos que transcendem o próprio universo escolar. A busca de construir não apenas modelos, mas modelos que incrementem nossas formas de construir a realidade, acrescenta uma mudança de "qualidade" ao conhecimento científico escolar (Pietrocola, 1999:12, grifos nossos).

O que o professor busca ao fazer uso de modelos ao trabalhar modelização com seus alunos é a melhoria da qualidade do ensino de ciências. Ou seja, melhorar a "qualidade do conhecimento científico escolar" ensinado, assegurando, assim, uma melhor relação com o mundo em que vivemos.

Os quatro pontos abaixo mostram, resumidamente, a importância dos modelos e o processo de modelização, já que os mesmos podem ser um meio de transformação dos conteúdos de ensino, pois:

a) se modeliza visando apreender o real; 
b) todo modelo científico se traduz como um incremento à compreensão da realidade do mundo;

c) assim como na ciência, a construção de modelos é resultado de um processo criativo mediado pelos/e entre os homens pela ação da razão e; d) a sala de aula deveria conter atividades de onde se passasse de um real imediato (forjado pelo senso comum) a um real idealizado pela ciência." (Pietrocola 1999:13).

Portanto, a modelização no ensino de CN\&T mostra-se além de útil, necessária. Mas, para isso a formação inicial dos professores precisa contemplar em seus currículos, disciplinas que propiciem aos futuros professores leituras dessas teorias para potencializar mudanças significativas no ensino de CN\&T.

\section{CADEIA ALIMENTAR COMO UM MODELO}

Um dos elementos fundamentais para a manutenção da vida é o alimento. Ele fornece aos organismos os componentes que participam de todos os processos bioquímicos responsáveis pela existência e pela continuidade da matéria viva.

Segundo Lopes (1999), na natureza, as plantas e outros seres clorofilados produzem, por fotossíntese, os alimentos de que necessitam e os degradam por meio da respiração para a execução das funções celulares, esses organismos são denominados autótrofos. Já os organismos que não conseguem produzir seus próprios alimentos, precisam se alimentar dos produtores (autótrofos) ou de outros consumidores (heterótrofos) ${ }^{6}$.

Esse elo alimentar entre os seres vivos pode ser facilmente observável na natureza: as plantas são consumidas pelos animais herbívoros, que são consumidos pelos

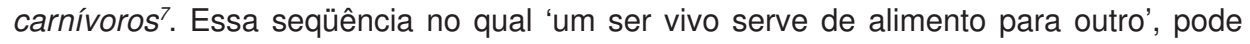
ser representada em forma de modelo no que se denomina de cadeia alimentar. Portanto, este modelo descreve também como ocorre a transferência de matéria e de energia entre os seres vivos numa cadeia alimentar.

Dessa maneira, dos conteúdos abordados em Ecologia, a Cadeia Alimentar representa "uma seqüência de organismos onde um serve de alimento para o outro, a partir do produtor". Uma forma de representar as cadeias alimentares é ligar os nomes dos organismos com setas ou colocar cada ser vivo num nível da pirâmide de energia (figura 1).

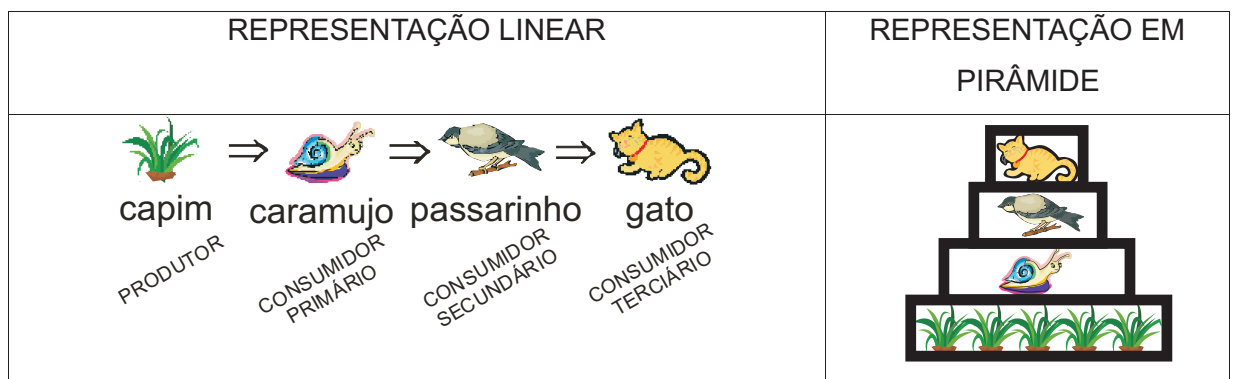

Figura 1: Duas possíveis representações de uma cadeia alimentar (figuras sem proporção de tamanho entre si)

${ }^{6}$ Os seres vivos de um ecossistema podem ser divididos em outótrofos e heterótrofos.

A maioria dos seres autótrofos (algas, plantas e certas bactérias) faz fotossíntese, captando energia luminosa do Sol e utilizando-a na fabricação de matéria orgânica. Existem, ainda, alguns poucos seres autótrofos que fazem quimiossíntese, como, por exemplo, certas bactérias, e obtêm energia para a vida através de reações químicas inorgânicas. Os animais, fungos, protozoários e a maioria das bactérias são heterótrofos, isto é, necessitam obter substâncias orgânicas (alimento) a partir de outros seres vivos ou de seus produtos.

${ }^{7}$ Animais herbívoros alimentam-se de plantas enquanto que os carnívoros alimentam-se de outros animais. 


\section{ensaio}

vol $8 \cdot \mathrm{n}^{\circ} 2 \cdot$ dez. 2006

Os modelos sugeridos para representação de uma Cadeia Alimentar e Pirâmide Alimentar, conforme os apresentados na figura 1, têm como propósito apresentar uma representação seqüencial linear, a partir de um vegetal, sugerindo que os animais menores são consumidos pelos maiores durante a sua alimentação para a sua sobrevivência (o que se constitui em um equívoco conceitual, pois nem sempre o consumidor é maior). Já na pirâmide, a representação dos níveis tróficos é uma representação de como a energia do alimento flui ao longo da cadeia alimentar.

No início de uma cadeia alimentar como na pirâmide, é obrigatória a presença de planta clorofilada, única capaz de absorver diretamente a energia da luz e nutrientes do solo e/ou da água. Essa energia, no entanto, diminui à medida que passa pelos consumidores, visto que uma parte dela é utilizada para a realização dos processos vitais do próprio organismo (respiração, digestão, circulação, etc) e a outra parte é liberada na forma de calor. Portanto, os organismos que se situam em níveis mais elevados recebem menor quantidade de energia. Na transferência de energia, através de um fluxo unidirecional, não há reaproveitamento da energia liberada, contudo a matéria pode ser reciclada, ou seja, uma cadeia é também uma representação de um ciclo de matéria (figura 2).

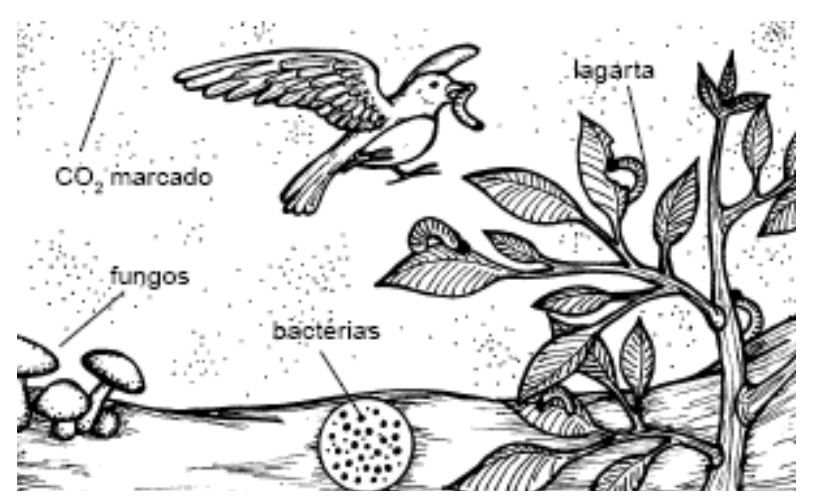

Figura 2: ambiente fechado com roseira, lagartas, pássaro, decompositores e gás carbônico marcado. (TELECURSO 2000, 2005)

Na cadeia alimentar ou na pirâmide são representados os níveis tróficos ${ }^{8}$. Cada nível é constituído por organismos que desempenham um papel diferente. Os organismos que constituem a base da cadeia alimentar, ou seja, o primeiro nível trófico é representado pelos autótrofos por serem produtores de alimentos, já o segundo nível trófico é representado pelos consumidores ou heterótrofos.

Os organismos que se alimentam dos produtores são os consumidores primários, e os organismos que se alimentam desses, são os consumidores secundários; os que se alimentam dos secundários são os consumidores terciários e assim sucessivamente.

Alguns animais alimentam-se tanto de vegetais quanto de animais, podendo dessa forma ocupar mais de um nível trófico. O homem é um exemplo, visto que quando este se alimenta de autótrofos (vegetais) ocupa o segundo nível trófico (consumidor primário). Quando se alimenta de carne (boi), ocupa o terceiro nível trófico (consumidor secundário).

Ao abordar o assunto cadeia alimentar, normalmente o(a) professor inicia o conteúdo a partir de um modelo, tendo implícita a "organização" de uma seqüência de

${ }^{8}$ Nível trófico - conjunto de organismos de um ecossistema com o mesmo tipo de nutrição. 
seres vivos que se relacionam de forma natural em busca de alimento à sua sobrevivência. Segundo Bunge (1974:16), cada modelo teórico, se constitui num sistema hipotético-dedutivo que corresponde a um objeto-modelo. O objeto-modelo representa os objetos-reais e o modelo teórico o comportamento deles. Temos desse modo, uma interpretação de parte da realidade, comum na Natureza, visto que os animais buscam alimentar-se de acordo com seus hábitos alimentares e sistema digestório para metabolizar seus alimentos.

Assim, no modelo da cadeia alimentar, os primeiros seres vivos são os vegetais, visto que esses, por meio da fotossíntese, conseguem fixar em sua estrutura (cloroplastos) a energia luminosa absorvida durante o dia.

No mesmo modelo, os animais aparecem após os vegetais, seguindo a indicação das setas, numa representação de animais que consomem outros animais, uma vez que estes não conseguem sintetizar seus alimentos; buscam dessa forma, alimentos prontos.

Em sala, alguns professores sentem certa insegurança em abordar este assunto - a cadeia alimentar, sem conhecer o modelo do livro ou de um texto de referência. Seria interessante que a conquista conceitual começasse por idealizações, buscando traços comuns de indivíduos ostensivamente diferentes, agrupando-os em espécies, nascimento do objeto-modelo ou modelo conceitual, pois, a formação de cada modelo começa por simplificações, mas a sucessão histórica dos modelos é um progresso de complexidade (Bunge, 1974).

Seria interessante o professor saber que somente modelos construídos por meio da intuição e da razão e submetidos à prova da experiência são bem sucedidos, e, sobretudo são suscetíveis de serem corrigidos segundo a necessidade (Bunge, 1974). Assim, a construção coletiva de uma cadeia alimentar a partir de organismos conhecidos pelos alunos se constitui numa oportunidade de experiência na qual a modelização aparece como atividade criadora.

\section{SITUAÇÃO DIDÁTICA}

\section{a) Descrição}

Descrevemos a partir de agora, a situação didática a ser analisada, desenvolvida nas aulas de CN\&T em uma 4ª série do Ensino Fundamental de uma escola pública de Florianópolis/SC. Atuavam nessa ocasião, duas professoras (a professora regente e uma colaboradora). A situação didática a ser analisada compõe um total de 4 aulas, sendo que na primeira a professora regente distribuiu diversos livros didáticos de $1^{\mathrm{a}}$ a 4a série solicitando que os alunos fizessem uma pesquisa sobre Cadeia Alimentar. Em grupo os alunos localizaram nos livros o assunto e copiaram as informações para seus cadernos, formando um pequeno texto. Já na segunda e terceira aula (que são as que nos interessam, juntamente com os resultados obtidos na avaliação escrita - prova na quarta aula), foram elaborados os planejamentos, que seguem abaixo, e seus respectivos relatos com atuação direta da professora colaboradora.

As aulas foram organizadas em três momentos pedagógicos de Delizoicov e Angotti (1990) que consistem em: 1) Problematização Inicial (PI), caracteriza-se por carregar um recorte temático e se apresenta sob a forma de um desafio ou problema a resolver; 2) Organização do Conhecimento (OC), momento no qual apresentamos os conceitos envolvidos no desafio inicial sob a forma de conteúdos escolares, organizado por ordem de prioridade e de responsabilidade do professor; 3) Aplicação do Conhecimento (AC), propomos aos alunos um novo problema envolvendo os conceitos científicos trabalhados na aula, ou seja, colocamos os alunos frente a novos desafios cuja resolução requer os conhecimentos estudados na aula em questão. 


\section{ensaio}

vol $8 \cdot \mathrm{n}^{\circ} 2 \cdot \operatorname{dez} .2006$

Os métodos e técnicas para coleta de dados foram: diários, que eram fechados em focos de observações pré-determinados, cuja função era descrever e função descrever e relatar as atividades curriculares, assim como a temática abordada, os aspectos científicos e tecnológicos e as condutas dos sujeitos envolvidos; análise de documentos, nesse caso os cadernos e provas escritas dos alunos; e observação participante, que teve por função potencializar não apenas a observação focada, mas também a participação ativa no contexto das aulas de CN\&T. Foram implementadas sob a forma de docência compartilhada, por meio da colaboração docente em momentos de planejamento, resolução de problemas e atividades em grupo dos alunos. Assim, podemos dizer que implementamos um processo de investigação-Ação Escolar, pois segundo Feldman \& Capobianco (2000), essa é considerada uma perspectiva de investigação utilizada tanto na formação do professor e no desenvolvimento profissional desse, nas investigações sobre ensino de ciências, quanto no desenvolvimento e implementação curricular.

Aula 1 (Tempo $45 \mathrm{~min}$ )

Faça uma pesquisa nos livros e escreva um texto explicando o que é uma cadeia alimentar. (atividade desenvolvida em grupo).

Aula 2 (Tempo $90 \mathrm{~min}$ )

Problematização Inicial - $(\mathrm{PI})$

Escreva um exemplo de uma cadeia alimentar utilizando apenas 3 seres vivos. (atividade desenvolvida individualmente)

Organização do Conhecimento - (OC)

a) A prof. explica as regras do "Jogo da cadeia alimentar" (Costa, CHC, $n^{\circ} 83$ ), montando uma tabela (tabela composta por 4 colunas indicando $n^{\circ}$ da rodada do jogo, $\mathrm{n}^{\circ}$ de produtor, consumidor primário, consumidor secundário).

b) Desenvolvimento do jogo conforme as orientações do texto "jogo da Cadeia" ( Costa $\mathrm{CHC}$ n?82)

c) Ler e discutir o texto "A teia da vida" Costa ( $\mathrm{CH}$ na Escola $\left.n^{\circ} 82\right)$.

d) Análise dos resultados da tabela.

Aplicação do Conhecimento - (AC)

Considerando os dados da tabela, escreva o que aconteceu com a cadeia alimentar do nosso jogo.

Relato ${ }^{9}$ aula 2: Na resolução da PI todos os alunos montaram uma cadeia, mas muitos fizeram a cadeia contrária ao fluxo de energia. Por exemplo: cachorro ? gato? rato. Fechamos essa etapa explicando a ordem hierárquica. Após explicarmos as regras do jogo fomos ao pátio para jogar. Realizamos 6 rodadas e obtivemos os dados para preenchimento da tabela.(...) Lemos o texto e destacamos as classificações de Produtor, Consumidor Primário, Secundário, Carnívoro, Herbívoro; Decompositores. Montamos uma pirâmide mostrando o fluxo de energia e analisamos a tabela concluindo que as capivaras estavam ameaçadas de extinção e consequentemente as onças. Encerramos mostrando a necessidade de uma alimentação variada dos carnívoros superiores.

Aula 3 (Tempo $90 \mathrm{~min}$ )

Problematização Inicial - (PI)

Escreva por que as cadeias alimentares devem começar pelas plantas.

${ }_{9}^{9}$ Todos os relatos foram elaborados pela professora colaboradora que implementou as aulas juntamente com a professora regente. 
Organização do Conhecimento - (OC)

a) Assistir fragmentos do vídeo "cadeia alimentar" aula 34 do Telecurso2000;

b) Ler o texto "Cadeia alimentar" (Costa, $\mathrm{CHC} \mathrm{n}^{\circ}$ 82) e abordar os conceitos:

1. produção de energia (plantas e animais);

2. fluxo de energia e ciclo de materiais (pirâmide e ciclo);

3. posição dos vegetais e animais na pirâmide (produtor, consumidor primário, consumidor secundário...)

Aplicação do Conhecimento - (AC)

Monte uma cadeia alimentar e faça a pirâmide de energia.

Relato aula 3: .... Ao fazermos a Pl percebemos que poucos alunos responderam corretamente ou próximo da resposta. Assistimos ao vídeo e os alunos acharam interessante, pois além de curto aparecia desenhos para ilustrar. Ao voltarmos à sala retomamos a PI para conferir as respostas. Nesse momento discutimos o processo de produção e aquisição de energia nas plantas e animais. Distribuímos o texto destacando os conceitos de Fluxo de energia e Ciclo de materiais. Após montamos uma cadeia e fizemos a distribuição na pirâmide de energia.(...) Executamos o AC sistematizando no quadro a resposta.

Aula 4 (Tempo $90 \mathrm{~min}$ )

Avaliação escrita obrigatória (Prova)

(Mesmo que a avaliação tenha ocorrido processualmente nos momentos de Aplicação do Conhecimento, fizemos um dia de prova escrita obrigatória pois precisávamos cumprir com as exigências institucionais.)

\section{b) Análise do processo de ensino aprendizagem mediado pelos modelos}

A situação didática descrita passa a ser analisada à luz da teoria e dos modelos que mediaram o processo de ensino. Foram tomados como base os dados descritos nos planejamentos e seus respectivos relatos de implementação dos conteúdos/ conceitos, juntamente com algumas respostas das questões da prova escrita aplicada.

Considerando a série de desenvolvimento da pesquisa (4⿳亠丷厂 série do ensino fundamental) as professoras partiram da premissa que os alunos já possuíam o que Bunge (1974) considera de objeto-modelo ou modelo conceitual, relativos ao tema em estudo. Ou seja, deveriam apresentar uma conquista conceitual, começando por idealizações, buscando traços comuns em indivíduos ostensivamente diferentes e agrupando-os em espécies. De fato, nas séries anteriores o que os alunos mais aprendem em termos de ensino de biologia são as características e a classificação ou agrupamento dos animais por espécies. Por isso, a solicitação de uma representação esquemática de uma cadeia alimentar (conforme Problematização Inicial aula 2), possibilitou o desenvolvimento criativo dos alunos, construindo assim, uma primeira modelização para o tema. Podemos conferir no relato dessa aula que "Na resolução da $P I$ todos os alunos montaram uma cadeia, mas muitos fizeram a cadeia contrária ao fluxo de energia. Por exemplo: cachorro ? gato ? rato".

O interessante é que nesse momento os alunos, por conhecimentos anteriores, já utilizavam as setas que representam o fluxo de energia, mesmo sem saber sua função. Ou seja, já tinham noções do modelo científico. Mas isso não era suficiente para a situação didática em desenvolvimento, pois o objetivo era ensinar "cadeia alimentar" em seus conceitos e teorias científicas envolvidos. Ou seja, que a cadeia alimentar é uma seqüência de organismos em que um serve de alimento para o outro, a partir do produtor. Nessa teoria está implícito o conceito de fluxo de energia e ciclo de materiais. 
Portanto, é nesse momento que se constrói o que Bunge (1974) denomina de objeto-modelo ou modelo conceitual, pois, um modelo conceitual inicia-se por simplificações, negligenciando numerosos traços. Ainda, segundo Bunge, para apreender o real é necessário afastar-se da informação, adicionando elementos imaginários ou hipotéticos. Constituindo assim, um objeto-modelo e que esse deverá ser enxertado por teorias suscetíveis de serem confrontadas com os fatos (Bunge, 1974).

Acreditamos que na aula 2 a construção de uma cadeia alimentar na forma de um jogo pelos alunos possibilitou além da simplificação do modelo, um afastamento da informação que se queria ensinar, possibilitando, assim que os alunos estabelecessem relações com os fatos reais.

Se observarmos as Problematizações Iniciais das duas aulas descritas, é possível perceber que houve uma preocupação em trabalhar os conceitos de Fluxo de Energia e Ciclo de Materiais, ama vez que as problematizações visavam montar uma cadeia alimentar e explicar porque ela deveria começar pelas plantas, ou seja, pelo produtor. Isso gerou discussões e conseqüentemente, explicações das teorias científicas envolvidas. Dessa forma, o desenvolvimento das aulas planejadas possibilitou a construção de um modelo-teórico para o objeto-modelo.

Para tanto, na aula 2 como na aula 3, as professoras usaram os seguintes modelos de cadeia alimentar: planta ? capivara ? onça ? fungos e bactérias e/ou planta? gafanhoto ? sapo ? cobra, utilizando os mesmos organismos para compor a pirâmide de energia e explicitar o ciclo de materiais, assim como para fazer a classificação em produtor, consumidor primário, secundário,....carnívoro, herbívoro.... Esses modelos são os mais freqüentes nos livros didáticos, principalmente de $1^{\underline{a}}$ a $4^{\underline{a}}$ séries do ensino fundamental. Eles aparecem tanto em forma linear, como a descrita acima, quanto com desenhos no lugar das palavras.

Podemos concluir que pelo fato do processo de aprendizagem não ser uniforme, o uso de modelos e modelizações no ensino de CN\&T pode potencializar o processo de ensino, pois é possível perceber que o uso consciente dessa "ferramenta" pelo professor possibilita uma maior compreensão e aquisição dos conceitos científicos por parte dos alunos. Tal fato foi constatado nas respostas dadas pela maioria dos alunos, na avaliação escrita.

Apenas três em uma turma de 25 não conseguiram romper com sua concepção inicial. Mesmo após o desenvolvimento das aulas esses alunos continuaram com seus modelos iniciais como verificamos nas respostas de três questões da prova, dadas por um desses alunos (anexo 1).

O que chamou atenção nessas respostas foi o fato de que o aluno não foi incoerente em nenhum momento, ou seja, ele manteve sua concepção inicial (invertida) em todas as respostas. Ao conversarmos, ele argumentou que era correta essa seqüência porque uma planta não come uma formiga, nem uma formiga come um tamanduá, como podemos observar na resposta da questão no 2 em anexo.

Portanto, pode-se dizer que o sistema cognoscitivo de um aluno é constituído pelo conjunto de representações da realidade e dos instrumentos intelectuais que permitem que ocorra tal construção dessas representações que o mesmo possui.

Por fim, cabe destacar que na nossa opinião, a maneira como se iniciou o trabalho com a temática em questão, passa a ser equivocada. Situações didáticas que partem de uma definição conceitual a partir de livros didáticos, não permitem idealizações, buscando traços comuns de indivíduos ostensivamente diferentes, agrupando-os em espécies, nascimento do objeto-modelo ou modelo conceitual (Bunge, 1974).

Seria mais conveniente iniciar esse trabalho a partir da segunda aula, ou seja, por aquelas planejadas conjuntamente entre a professora regente e os professores pesquisadores e autores deste artigo. Como já dissemos anteriormente, somente modelos construídos por meio da intuição e da razão e submetidos à prova da experiência 
são bem sucedidos e, sobretudo, são suscetíveis de serem corrigidos segundo a necessidade (Bunge, 1974). Para isso, a organização didático-metodologia dos momentos pedagógicos mostra-se conveniente, pois a partir das problematizações iniciais é possível verificar os modelos prévios dos alunos e assim trabalhar na perspectiva do desenvolvimento conceitual.

\section{CONCLUSÕES}

A aprendizagem em CN\&T não deveria limitar-se a oferecer trocas de concepções pre-estabelecidas e selecionadas pelos docentes, e sim tentar encontrar estratégias que facilitassem ao estudante modificá-las, assim como seus esquemas interpretativos, de forma autônoma, cada vez que a situação problema o desafiasse.

Assim, o uso de modelos e modelizações não como atividade meramente racional e mecânica, mas com objetivo de partir da observação e resgate das concepções dos alunos, possibilitará uma melhor compreensão dos assuntos científicos. Para tanto, é necessário que nos objetivos de ensino sejam considerados não apenas os modelos conceituais ensinados, mas os modelos mentais construídos pelos alunos, visto que os modelos mentais ensinados devem produzir as mesmas explicações, por exemplo, sobre uma cadeia alimentar gerada pelo modelo conceitual.

Os Parâmetros Curriculares Nacionais (PCN) apontam que os conceitos da Ecologia, por exemplo, são construções teóricas e não fenômenos observáveis ou passíveis de experimentação. E que esse é o caso das cadeias alimentares, do fluxo de energia, da fotossíntese, da adaptação dos seres vivos ao ambiente... Afirmam que "não são aspectos que possam ser vistos diretamente, só podem ser interpretados, são idéias construídas com o auxílio de outras mais simples, de menor grau de abstração, que podem, ao menos parcialmente, ser objeto de investigação por meio da observação e da experimentação direta" (Brasil, 1997:49). Ou seja, faz-se necessário o processo de modelização dessas teorias através de construção teórica substitutiva em relação aos dados empíricos e figurações visuais como maquetes, simulações ou jogos, como o realizado por nós na aula 2 .

A aprendizagem significativa dos conhecimentos teóricos é indissociável de uma familiarização com os objetivos, sistemas de valores, critérios metodológicos, estratégias cognoscitivas, concepções epistemológicas que intervêm na construção de tal conhecimento.

No passado, aprendiam-se ciências, pois havia a crença que através delas seria possível se chegar a desvelar segredos da natureza. Esse objetivo estaria associado à apreensão de conhecimento científico independentemente dos aspectos pragmáticos, utilitaristas e adequados a qualquer educação propedêutica. A falta de vinculação do ensino das ciências com o mundo não é algo novo. Pesquisas na área de ensino de ciências têm apontado como os conteúdos científicos são tratados pelos professores numa concepção excessivamente formal. Nela, segundo Pietrocola (1999), os alunos participam de uma espécie de jogo cujas regras e táticas só são pertinentes ao contexto escolar.

No ensino de ciências, o assunto cadeia alimentar, conforme relato da situação didática, é um assunto relativamente conhecido pelos alunos, ou seja, as crianças têm conhecimento que na Natureza os seres vivos se relacionam em função do tipo de alimento e que os organismos maiores normalmente consomem os menores. As observações que as crianças realizam no meio e as construções que essas tecem sobre o mundo onde vivem, originam concepções que permitem a elas, muitas vezes, realizar previsões e explicar fenômenos que o cercam.

No estudo das concepções alternativas, os pesquisadores têm focalizado o conteúdo das representações dos estudantes. Um modelo é, portanto, segundo Giordan 
(1996), uma construção, uma estrutura que pode ser utilizada como referência, uma imagem analógica que permite materializar uma idéia ou um conceito, tornando-os, assim, diretamente assimiláveis.

Um modelo, porém, não deve servir apenas para aclarar um conjunto de elementos, mas deve auxiliar e aclarar um conjunto de elementos, como também, permitir a elaboração de previsões e ser usado em situações diversas. É importante que o aluno compreenda que o modelo representa uma espécie de "sistema experimental in vitro", sobre o qual se pode raciocinar, manipular, observar, mas que esse não é a realidade em si. A ciência contemporânea produz a cada momento mais e mais modelos, exemplo DNA, átomo e outros assegurando uma melhor compreensão do mundo em que vivemos.

Hoje, a melhoria no ensino de ciências naturais, para que esse seja mais motivador, interessante e atenda às necessidades dos estudantes, tem sido um desafio de educadores não apenas construtivistas, mas também de outros pesquisadores de ensino relacionados com a prática educativa.

Dessa maneira, podemos dizer que a situação didática em questão foi um momento de formação continuada para todos os professores envolvidos. Foi possível observar que mesmo a professora regente não dispondo de 'conhecimentos sobre teorias de modelos e modelização no ensino de ciências', acompanhou e incorporou essa maneira de ensinar-aprender. Por outro lado, os demais professores (autores deste texto) tiveram contato com esse conhecimento teórico no decorrer da situação didática descrita, sendo assim iniciantes no processo.

Por fim, os modelos devem ser utilizados como recursos aproximativos e não como realidades; como instrumentos de explicação e previsão produzidos com a intenção de uma melhor compreensão dos problemas educativos enfrentados. Nesse processo, é fundamental o papel do professor em implementar as necessárias situações de interação e em fazer construir, ou solicitar aos alunos ferramentas mais adequadas.

Reconhece-se, assim, segundo Giordan (1996), a eficácia num determinado modelo na construção do saber científico, quando os alunos podem estabelecer relações, elementos esparsos de seus conhecimentos anteriores, e sobretudo, quando ocorre a formulação de novas perguntas sobre o assunto que não ocorriam antes da introdução dos modelos.

Embora o uso de modelos ou a modelização se constituam em "instrumentos" facilitadores à compreensão dos conteúdos de ensino, esses ainda não se constituem como uma prática presente nos cursos de formação inicial de professores. Portanto, não se pode esperar que a curto prazo esses produzam efeitos significativos na aprendizagem de CN\&T.

Assim, é necessário que os professores em cursos de formação 'aprendam' ou compreendam a necessidade de vincular e relacionar os conteúdos ensinados com situações do dia a dia do aluno. Dessa forma, o ensino de CN\&T passará a vincular-se ao cotidiano e por conseqüência, também à realidade do aluno. Dessa maneira, tanto a ciência como a escola, estarão mais próximos de cumprirem seus objetivos básicos oferecer um ensino aos seus alunos para que esses possam entender o contexto em que vivem, continuar sua escolaridade ou mesmo poder trabalhar com um aporte de conhecimentos que os ajude a enfrentar os desafios presentes no uso de equipamentos e instrumentos do atual contexto social. 


\section{REFERÊNCIAS BIBLIOGRAFICAS}

ASTOLFI, J. P. e DEVELAY, M. A didática das ciências. São Paulo: Papirus, 2001.

BASSANEZI, R. A modelagem matemática. Dynamis, Blumenau, 1 (7), 55-83, abr/jun, 1994.

BRASIL, Secretaria da Educação Fundamental. Parâmetros Curriculares Nacionais: Ciências Naturias. Secretaria da Educação Fundamental . Brasília: MEC/SEF, 1997, 126p. (em URL: http://www.mec.gov.br) .

BUNGE, M. Teoria e realidade. São Paulo: Perspectiva, 1974.

COSTA, V.R. Por dentro das cadeias alimentares. Ciência Hoje na Escola. Disponível em http://www.uol.com.br/cienciahoje/che/cadeia.htm .

COSTA, V.R. A teia da vida. Ciência Hoje na Escola. Disponível em http://www.uol.com.br/ cienciahoje/che/cadeia2.htm.

COSTA, V.R. Jogo da Cadeia. Ciência Hoje das Crianças, n. 82.

DELIZOICOV, D. e ANGOTTI, J. A. Metodologia do ensino de ciências. São Paulo: Cortez, 1990.

FELDMAN A \& CAPOBIANCO B. Action Research in Science Education. ERIC Clearinghouse for Science, Mathematics, and Environmental Education. October 2000. Disponível em <http://www.ericse.org/digest/dse00-01.htm> . Acessado em 05/10/2002.

FOUREZ, G. Alfabetización Cientifica y Tecnológica: acerca de las finalidades de las enseñanza de las ciencias. Ediciones Colihue, Buenos Aires, Argentina, 1997.

GIORDAN, A. As origens do saber das concepções dos aprendentes aos conceitos científicos. Porto Alegre : Artes Médicas, 1996.

LOPES, S. Bio. Volume Único, Editora Saraiva, São Paulo, 1999.

MARTINAND, J.L. Enseñanza y Aprendizaje de la Modelizacion. Enseñanza de las Ciencias, 1986, 4 (1), 45-50.

PIETROCOLA, M. Construção e Realidade: o realismo científico de Mário Bunge e o ensino de ciências através de modelos. Investigações em ensino de Ciências. Vol. 4, n. 3, dezembro de 1999. Disponível on line em http://www.if.ufrgs.br/public/ensino/

PINHEIRO, T. F., Aproximação entre a Ciência do Aluno na Sala de Aula da 1a Série do $2^{\circ}$ Grau e a Ciência dos Cientistas: Uma Discussão. Dissertação de Mestrado em Educação, Florianópolis, UFSC, 1996.

PINHEIRO, T. F., e outros. Modelização de variáveis: uma maneira de caracterizar o papel estruturador da Matemática no conhecimento científico.In: PIETROCOLA, M. Ensino de física: conteúdo, metodologia e epistemologia numa concepção integradora. Florianópolis: Ed. da UFSC, 2001.

PINHO ALVES, J. e PIETROCOLA, M. Instrumentação para o Ensino de Física. Florianópolis: Laboratório de Ensino a Distância, 2001.

TELECURSO 2000, Os ajudantes invisíveis. Aula 32. Biblioteca Virtual do Futuro. São Paulo: USP, 2005. Disponível on-line em http://www.bibvirt.futuro.usp.br/textos/ biologicas/ biologia/tc2000/bio32.pdf 


\section{ensaio}

vol $8 \cdot \mathrm{n}^{\circ} 2 \cdot$ dez. 2006

\section{ANEXOS}

Algumas questões da avaliação escrita obrigatória (Prova)

1- O que você entende por cadeia alimentar?

Resposta: Cadeia alimentar é algo da natureza, é parecido com o ciclo vital. 0 maior come o menor.

2- Construa uma cadeia alimentar composta por formigas, tamanduá, grama e onça. (Não se esqueça das setas). Classifique cada ser vivo de acordo com seu papel na cadeia:

Resposta:

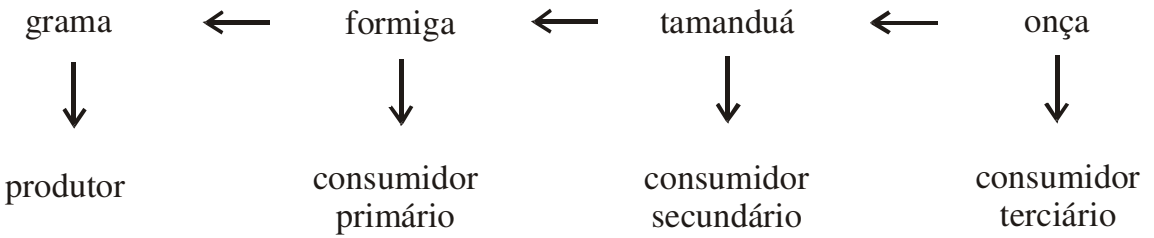

8- Coloque em ordem os grupos de seres vivos abaixo, formando com cada um deles uma cadeia alimentar:

a) cobra, milho, rato, gavião

Resposta:

gavião $\longrightarrow$ cobra $\longrightarrow$ rato $\longrightarrow$ milho

b) peixe, algas, foca

Resposta:

foca $\longrightarrow$ peixe $\longrightarrow$ algas

c) capim, cobra, sapo, besouro, fungos e bactérias

Resposta:

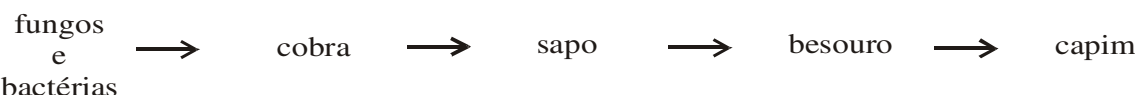

Observação: na questão $n$ ?2, as setas foram postas pelo aluno. Já na $n$ ?8, as setas foram postas pela professora, cabendo ao aluno apenas a tarefa de preencher os espaços entre as setas com os nomes dos seres vivos apresentados aleatoriamente nas letras $a, b$ e $c$.

Data de recebimento: 14/12/2005

Data de aprovação: 31/07/2006 